\title{
Climate Projections Over Different Climatic Regions of Afghanistan for Shared Socioeconomic Scenarios
}

\author{
Mohammad Naser Sediqi ( $\square$ mohammad.naser.sediqi.p4@dc.tohoku.ac.jp) \\ Tohoku University Graduate School of Environmental Studies: Tohoku Daigaku Daigakuin Kankyo Kagaku Kenkyuka \\ https://orcid.org/0000-0002-3569-161X \\ Vempi Satriya Adi Hendrawan \\ Tohoku University Graduate School of Environmental Studies: Tohoku Daigaku Daigakuin Kankyo Kagaku Kenkyuka \\ Daisuke Komori \\ Tohoku University Graduate School of Environmental Studies: Tohoku Daigaku Daigakuin Kankyo Kagaku Kenkyuka
}

\section{Research Article}

Keywords: CMIP6, shared socioeconomic pathways, model's skill assessment, compromise programming

Posted Date: January 5th, 2022

DOI: https://doi.org/10.21203/rs.3.rs-1202436/v1

License: (1) (1) This work is licensed under a Creative Commons Attribution 4.0 International License. Read Full License 


\section{Abstract}

The global climate models (GCMs) of Coupled Model Intercomparison Project phase 6 (CMIP6) were used spatiotemporal projections of precipitation and temperature over Afghanistan for three shared socioeconomic pathways (SSP1-2.6, 2-4.5 and 5-8.5) and two future time horizons, early (2020-2059) and late (2060-2099). The Compromise Programming (CP) approach was employed to order the GCMs based on their skill to replicate precipitation and temperature climatology for the reference period (1975-2014). Three models, namely ACCESS-CM2, MPI-ESM1-2-LR, and FIO-ESM-2-0, showed the highest skill in simulating all three variables, and therefore, were chosen for the future projections. The ensemble mean of the GCMs showed an increase in maximum temperature by 1.5-2.5 ${ }^{\circ} \mathrm{C}, 2.7-4.3^{\circ} \mathrm{C}$, and $4.5-5.3^{\circ} \mathrm{C}$ and minimum temperature by $1.3-1.8^{\circ} \mathrm{C}, 2.2-3.5^{\circ} \mathrm{C}$, and $4.6-5.2{ }^{\circ} \mathrm{C}$ for SSP1-2.6, SSP2-4.5, and SSP5-8.5, respectively in the later period. Meanwhile, the changes in precipitation in the range of $-15-18 \%,-36-47 \%$ and $-40-68 \%$ for SSP1-2.6, SSP2-4.5, and SSP5-8.5, respectively. The temperature and precipitation were projected to increase in the highlands and decrease over the deserts, indicating dry regions would be drier and wet regions wetter.

\section{Introduction}

Climate change is a major environmental concern globally, particularly in dry areas (Rao et al., 2019; Lyimo \& Kangalawe, 2011; Ahmed, Shahid, et al., 2019; Rahman et al., 2018; Aich et al., 2017). With an arid to semi-arid-dominated climate, Afghanistan has experienced a large shift in the climate in recent decades (Omerkhil et al., 2020; Mohanty et al., 2012). The global climate risk index (2017) ranked Afghanistan the 12th vulnerable country to climate risk. The average temperature of Afghanistan showed a rise by 0.13 to $0.29^{\circ} \mathrm{C} /$ decade in the last fifty years (Savage et al., 2009). The country has also experienced the impacts of climate change, particularly prolonged droughts and severe water stress in recent years (Muhammad et al., 2017). In Afghanistan, 98\% of water resource is used for agriculture, and more than $80 \%$ of the population get their income from agricultural practices (Sediqi et al., 2019). Therefore, a sharp reduction of available water resources has severely affected the agriculture and agriculture-dependent population and economy. Understanding the possible climate changes is crucial to antedate forthcoming water strain and resulting consequences in agroeconomy. Climate change assessment in Afghanistan has several specific challenges (1) lack of sufficiently dense, long term and reliable historical meteorological records due to the four last decades of insecurity and civil war, and (2) geographical characteristics, complex topography, and different climatic regions (Savage et al., 2009). Therefore, these make it challenging to assess climate change implications in the country.

Several tools are available to reproduce historical climate or project future climate changes. Global Climate Models (GCMs) of Coupled Model Intercomparison Project (CMIP) is one of the fundamental tools to reproduce the climate pattern (Shiru et al., 2020; Salman et al., 2018). The GCMs simulate climate considering several scenarios of carbon emissions, and land use and socioeconomic alterations (Dessai \& Hulme, 2007). The global carbon releases and socioeconomic changes are related to the national, regional, and global political strategies. Afghanistan has two distinct regions, mountains and deserts, with completely different climates on annual and seasonal scales. The present study attempted to analyze the historical and future climate simulations for different climatic regions in Afghanistan.

A few studies have evaluated Afghanistan's historical and future climate change (Aich et al., 2017; Qutbudin et al., 2019; Sidiqi et al., 2018; Hassanyar \& Tsutsumi, 2017) and its impact on water resources and agriculture (Ghulami, 2018). However, those were based on GCMs of CMIP5 and representative concentration pathway (RCP). No studies have been conducted yet to assess historical and future climate over Afghanistan using CMIP6, the latest CMIP dataset phase with around 55 GCMs (Iqbal et al., 2021). Compared to CMIP5 and CMIP3 datasets based on radiative forcing and carbon releases, the CMIP6 employs a set of Shared Socioeconomic Pathways (SSP) to the updated version of coupled global climate models. CMIP6 GCMs consider different mitigation and climate change adaptation based on projected population changes, economic development, ecosystem, and social aspects. It also would reduce the bias in GCMs of the earlier phases of CMIP. Several recent studies have reported the improvement of CMIP6 compared to its earlier version (Hamed, 2021; Kamruzzaman et al., 2021; Song et al., 2021). For instance, (Zamani et al., 2020) reported that CMIP6 GCMs' ensemble outperformed CMIP5 and the relative bias of winter rainfall in all stations of northeastern Iran was much lower than CMIP5. Other studies also revealed improvement of CMIP6 for simulation of summer precipitation over East Asian monsoon and China (Xin et al., 2020). For this reason, it's significant to assess the historical and future climate pattern over Afghanistan using CMIP6.

The use of many GCMs for climate projection is often not preferred due to the large uncertainty associated with each GCMs and human and computational constraints (Shiru, Shahid, Dewan, et al., 2020). Therefore, an ensemble set of GCM with a minimum range of uncertainty is chosen. There are usually two basic ways to select suitable GCM: past-performance where skilled GCMs are identified 
according to their capacity to simulate the present climate and envelopes where GCMs are chosen according to their agreement in projections (Salman et al., 2018). This study used the past-performance method, as it is most widely used in literature, for the GCM selection.

The GCMs skills are evaluated based on their ability to simulate precipitation and temperature climatology over Afghanistan at annual and seasonal scales. The selected GCMs were used for future climate projections over different climate regions of Afghanistan. The paper is organized as follows: Section 2 describes the study area and datasets. Section 3 outlines the method adopted. Section 4 presents the outcomes, Section 5 discusses the results, and Section 6 provides conclusions.

\section{Study Area And Datasets}

\subsection{Geography of Afghanistan}

Afghanistan (latitude: $29^{\circ}-39^{\circ} \mathrm{N}$ and longitude: $60^{\circ}-75^{\circ} \mathrm{E}$ ) encompasses a land of around 652 thousand $\mathrm{km}^{2}$ (Nengroo et al., 2012). Afghanistan is a landlocked country (Fig. 1), bordered by Turkmenistan, Uzbekistan, Tajikistan in the north, Pakistan in the southeast, Iran in the west, and a small border with China to the northeast (Tschudin, 2008). Decades of political fighting has faced many different environmental issues, mostly in the water sector (Savage et al., 2009). Hindu Kush mountains dominate the topography of Afghanistan (Manawi et al., 2020;(Tschudin, 2008). Based on the ecoregion zoning provided by the World Wildlife Fund (Olson et al., 2001), Afghanistan is divided into five different climate zones (Fig. 1). The northeastern, predominantly mountainous Hindu Kush is the highest and coldest region that experiences the highest precipitation than the rest of Afghanistan. Northern Plains region in the north of central part the extends from Pamir near the border with Tajikistan up to the east with Iranian border. This region has around $50 \%$ rangeland, where only less than $10 \%$ is used for agriculture (Aich et al., 2017). Central Highlands are foothills of the Hindu Kush mountain range, which includes two central provinces: Bamyan and Daykundi. This region has elevated up to $6500 \mathrm{~m}$. Agricultural activities in the region are on a small scale as the large area is covered by rangelands. Southern Plateau covers a large area of the country made of arid deserts. Helmand River, the largest river in Afghanistan, crosses from the southern plateau. Eastern Highland borders with Pakistan have a hot summer, but it's the only region of the country influenced by the Indian monsoon that makes it appropriate for agriculture. Table 1 provides the details of each climatic region.

Afghanistan consists of four seasons: wet and freezing winter (Nov-Feb) and hot and dry summer (Jun-Aug) (Omerkhil et al., 2020). The other two are the transitional periods between winter and summer. The yearly rainfall ranges between $1000 \mathrm{~mm}$ in the northeast (Pular tundra zone) and below $50 \mathrm{~mm}$ in the south (arid desert zone). The northeast region experiences the minimum average temperature $\left(<-5^{\circ} \mathrm{C}\right)$, and the southwest (arid desert) region the highest $\left(>28^{\circ} \mathrm{C}\right)$.

Table 1

The climate classification of Afghanistan.

\begin{tabular}{|llll|}
\hline Climatic Zone & Mean precipitation $(\mathrm{mm} /$ year) & Average Annual Temperature $\left({ }^{\circ} \mathrm{C}\right)$ & Area $\left(\mathrm{Km}^{2}\right)$ \\
\hline 1 Hindu Kush & 517 & 1.4 & 45000 \\
\hline 2 Northern Plains & 267 & 15.9 & 190000 \\
\hline 3 Central Highlands & 347 & 9.5 & 125000 \\
\hline 4 Eastern Highlands & 466 & 14.9 & 72000 \\
\hline 5 Southern Plateau & 136 & 20.8 & 215000 \\
\hline
\end{tabular}

\subsection{Datasets}

\subsubsection{Observed data}

Global gridded climate data can be used for climate research in areas with a poor long-term record of climatic observation. Therefore, the present study utilized the Global Precipitation Climatology Centre (GPCC) monthly precipitation (Pre) accessible via https://psl.noaa.gov/data/gridded/data.gpcc.html and Climatic Research Unit (CRU) monthly maximum (Tmx) and minimum (Tmn) temperature data (Harris et al., 2014). The CRU data are available at https://crudata.uea.ac.uk/cru/data/hrg/cru_ts_4.03/. The Pre, 
Tmx, and Tmn datasets were collected from 1975 to 2014 with a resolution of $1^{\circ} \times 1^{\circ}$ from 90 grid points to cover Afghanistan. These data were used to select GCMs according to their skill in simulating Pre, Tmx, and Tmn.

CRU dataset was selected due to its multiple advantages. The database was made using nearly 4000 monitoring stations spread over the world. The suitability of CRU data has been verified over Afghanistan in literature (HASSANYAR et al., 2020; HAJIHOSEINI et al., 2015; H. Hassanyar et al., 2016). GPCC Pre also uses the highest rainfall records for developing gridded Pre datasets. It has been widely used for precipitation studies globally, including in Afghanistan.

Figure 2 shows the maps of annual, summer, and winter average Pre, Tmx, and Tmn over Afghanistan. Figure 3 represents the seasonal precipitation and temperature of different climatic regions during the reference period (1975-2014). Tmx in zone 1 (Hindu Kush region) has experienced the lowest Tmx, while in zone 2 (Southern Plateau), it goes up to $43^{\circ} \mathrm{C}$. The Southern Plateau region experiences the highest daily Tmn while it goes down to $-5^{\circ} \mathrm{C}$ in zone 1 (Hindu Kush region). Zones 1 and 4 receive the highest annual Pre, while zone 5 gets the lowest Pre during the summer.

\subsubsection{CMIP6 datasets}

The Pre, Tmx, and Tmn of CMIP6 GCMs were employed in the present study. Nineteen GCMs were used in the present study considering their availability of projections for Pre, Tmx, and Tmn for SSP1-2.6, 2-4.5, and 5-8.5. The basic description of selected GCMs is listed in Table. 2 CMIP-GCMs used in this study.. The GCMs monthly simulations of the three variables were gathered from CMIP6 portals (https://esgf-node.llnl.gov/search/cmip6/).

Table 2

CMIP-GCMs used in this study.

\begin{tabular}{|llll|}
\hline No & CMIP6 Model & Country & $\begin{array}{l}\text { Resolution } \\
(\text { Lon } \times \text { Lat) }\end{array}$ \\
\hline 1 & ACCESS-CM2 & Australia & $1.9^{\circ} \times 1.3^{\circ}$ \\
\hline 2 & ACCESS-ESM1-5 & Australia & $1.9^{\circ} \times 1.2^{\circ}$ \\
\hline 3 & AWI-CM-1-1-MR & Germany & $0.9^{\circ} \times 1.9^{\circ}$ \\
\hline 4 & BCC-CSM2-MR & China & $1.1^{\circ} \times 1.1^{\circ}$ \\
\hline 5 & CanESM5 & Canada & $2.8^{\circ} \times 2.8^{\circ}$ \\
\hline 6 & CIESM & China & $0.9^{\circ} \times 1.3^{\circ}$ \\
\hline 7 & CMCC-CM2-SR5 & Italy & $1.3^{\circ} \times 0.9^{\circ}$ \\
\hline 8 & EC-Earth3 & Europe & $0.7^{\circ} \times 0.7^{\circ}$ \\
\hline 9 & EC-Earth3-Veg & Europe & $0.7^{\circ} \times 0.7^{\circ}$ \\
\hline 10 & FGOALS-g3 & China & $2.0^{\circ} \times 2.3^{\circ}$ \\
\hline 11 & FIO-ESM-2-0 & China & $1.3^{\circ} \times 0.9^{\circ}$ \\
\hline 12 & INM-CM4-8 & Russia & $2.0 \times 1.5^{\circ}$ \\
\hline 13 & INM-CM5-0 & Russia & $2.0 \times 1.5^{\circ}$ \\
\hline 14 & IPSL-CM6A-LR & France & $2.5 \times 1.3^{\circ}$ \\
\hline 15 & MIROC6 & Japan & $1.4 \times 1.4^{\circ}$ \\
\hline 16 & MPI-ESM1-2-HR & Germany & $0.9 \times 0.9^{\circ}$ \\
\hline 17 & MPI-ESM1-2-LR & Germany & $1.9 \times 1.9^{\circ}$ \\
\hline 18 & MRI-ESM2-0 & Japan & $1.1 \times 1.1^{\circ}$ \\
\hline 19 & NESM3 & China & $1.9 \times 1.9^{\circ}$ \\
\hline & & & \\
\hline
\end{tabular}




\section{Methodology}

\subsubsection{Procedure}

The procedure adopted in the present study for selecting, downscaling, and preparing multimodel ensemble (MME) of GCMs, and projection of Pre, Tmx, and Tmn using MME are outlined below:

1. The simulated historical Pre, Tmx, and Tmn of $19 \mathrm{GCMs}$ for $1975-2014$ were re-gridded to a common resolution of $1^{\circ} \times 1^{\circ}$, as it is near the mean resolution of the models used. The GPCC/CRU data was also aggregated to $1^{\circ} \times 1^{\circ}$ resolution.

2. Compromise Programming (CP) was applied to compare GCMs with GPCC/CRU data to identify a GCM subset, according to their skill in replicating GPCC Pre and CRU Tmx and Tmn.

3. The selected GCMs were downscaled to the GPCC/CRU resolution of $0.5^{\circ}$. Bias in GCMs simulation was corrected using quantile delta mapping (QDM), considering the GPCC Pre and CRU Tmx and Tmn as a reference.

4. The bias-corrected GCM simulations were used for calculating MME mean projections for SSP1-2.6, 2-4.5, and 5-8.5.

5. Changes in Pre, Tmx, and Tmn for future periods compared to the reference period were used to show climate change in different climatic regions for three SSPs.

\subsubsection{Compromise programming}

Compromise programming (CP) (Zeleny, M., \& Cochrane, 1973) is employed in this study to combine the performance of GCMs based on multiple statistical metrics. CP calculates the combined effect of the different statistical performance indexes, as below:

$$
C I=\left[\sum_{i=0}^{i}\left|f_{j}^{*}-f_{j}\right|^{p}\right]^{\frac{1}{P}}
$$

1

where, $f_{j}$ is a value of statistical metric $j$ of a GCM, $f_{j}^{*}$ is the optimum value of the metric $j$ and $P$ is a parameter that can have a value $\geq$ 1. In this study, $P$ equal to 1 was considered. $\mathrm{Cl}$ near to zero indicates better performance.

The $\mathrm{Cl}$ was estimated using three statistical metrics in this study, (1) Kling-Gupta efficiency (KGE, Eq. 2), (2) coefficient (CC, Eq. 3), and (3) skill score (SS, Eq. 4) (Perkins et al. 2007):

$K G E=1-\sqrt{(C C+1)^{2}+\left(\frac{\mu_{s}}{\mu_{o}}-1\right)^{2}+\left(\frac{\sigma_{s} / \mu_{s}}{\sigma_{o} / \mu_{o}}-1\right)^{2}}$

$\mathrm{SS}=\sum_{n=1}^{N_{b}} \min \left(F S_{n}, F O_{n}\right)(4)$

where $\mu$ and $\sigma$ represent the average and the standard deviation of model simulations (s) and GPCC/CRU data (o); $F s_{n}$ and $F o_{n}$ are normalized frequency of GCM and GPCC/CRU data.

The $\mathrm{Cl}$ for Pr, Tmax, and Tmin was estimated individually to rank them based on each variable. The final rank of the GCMs was evaluated using a rating metric $(M R)$,

$$
M R=1-\frac{1}{n m} \sum_{i=1}^{n} \operatorname{rank}_{i}
$$

5

where, $m$ is the GCM number, $n$ of variables and $i$ is the rank of each GCM in $i$-th variables.

\subsubsection{Downscaling and projection of rainfall and temperature}


The Pre, Tmx, and Tmn of the selected GCMs were interpolated to GPCC/CRU points and bias-corrected using GPCC/CRU data. The quantile delta mapping (QDM) was used for this purpose,

$$
Q_{m}(t)=F_{0}^{-1}\left[F_{S}\left[Q_{S}(t)\right]\right]
$$

6

where, $Q_{m}(t)$ and $Q_{s}(t)$ are ith bias-corrected and GCM simulated data, $F_{S}$ and $F_{0}^{-1}$ are Cumulative distribution function (CDF) of raw GCM and inverse CDF of GPCC/CRU gridded data, respectively. During the period $1975-2014,70 \%$ of the data was used for developing the QDM model, and the rest was employed for QDM model evaluation.

\subsubsection{Generation of GCM ensemble projection}

The bias-corrected GCMs projections were used to prepare MME mean to lessen the uncertainty related to individual GCM. The MME was employed to estimate the percentage changes in Pre and the absolute changes in Tmx and Tmn in two future time horizons, near (2020-2059) and far (2060-2099), compared to the reference period, 1975-2014, for all SSPs. The changes were estimated for annual and seasonal scales. The results were presented using maps to show the spatial pattern of the changes.

\section{Results}

\subsection{Selection of GCMs}

Table 3 presents the GCMs' skill in replicating Pre, Tmx, and Tmn based on three statistics. The GCMs' skill based on each variable is shown in (Fig. 4). The results showed good performance of some models in simulating one variable but low for another. For example, EC-Earth3-Veg showed good skill in simulating Pre (blue) but low for both Tmx (red) and Tmn (green). Therefore, RM was employed for the final ordering of the GCMs. Black colored bars in (Fig. 4) show the GCM ranking based on RM. The results showed MPI-ESM1-2-LR as the most skilled model in replicating Afghanistan's observed climate, followed by ACCESS-CM2 and FIO-ESM-2-0. Therefore, these three GCMs can be considered best suited for the climate projection of the country. 
Table 3

Statistical performance indicators, SS, KGE, and CC of GCMs rainfall, maximum temperature and minimum temperature.

\begin{tabular}{|c|c|c|c|c|c|c|c|c|c|}
\hline \multirow[t]{3}{*}{ GCMs } & \multicolumn{9}{|c|}{ Performance Indicators } \\
\hline & \multicolumn{3}{|l|}{ Pre } & \multicolumn{3}{|l|}{$\operatorname{Tmx}$} & \multicolumn{3}{|l|}{ Tmn } \\
\hline & $\mathrm{CC}$ & KGE & SS & $\mathrm{CC}$ & KGE & SS & $\mathrm{CC}$ & KGE & SS \\
\hline ACCESS-CM2 & 0.81 & 0.78 & 0.94 & 0.95 & 0.91 & 0.99 & 0.97 & 0.83 & 0.93 \\
\hline ACCESS-ESM1-5 & 0.75 & 0.44 & 0.82 & 0.96 & 0.90 & 1.00 & 0.92 & 0.83 & 0.95 \\
\hline AWI-CM-1-1-MR & 0.79 & 0.66 & 0.93 & 0.94 & 0.89 & 0.97 & 0.97 & 0.74 & 0.96 \\
\hline BCC-CSM2-MR & 0.77 & 0.51 & 0.90 & 0.95 & 0.86 & 0.98 & 0.94 & 0.74 & 0.94 \\
\hline CanESM5 & 0.68 & 0.50 & 0.87 & 0.93 & 0.85 & 0.99 & 0.88 & 0.78 & 0.94 \\
\hline CIESM & 0.72 & 0.40 & 0.60 & 0.97 & 0.77 & 0.97 & 0.92 & 0.71 & 0.96 \\
\hline CMCC-CM2-SR5 & 0.75 & 0.59 & 0.90 & 0.93 & 0.82 & 0.99 & 0.89 & 0.56 & 0.88 \\
\hline EC-Earth3 & 0.91 & 0.80 & 0.97 & 0.93 & 0.80 & 0.98 & 0.86 & 0.53 & 0.85 \\
\hline EC-Earth3-Veg & 0.91 & 0.81 & 0.97 & 0.98 & 0.75 & 0.98 & 0.94 & 0.41 & 0.81 \\
\hline FGOALS-g3 & 0.55 & 0.35 & 0.88 & 0.88 & 0.80 & 0.98 & 0.92 & 0.34 & 0.87 \\
\hline FIO-ESM-2-0 & 0.76 & 0.75 & 0.92 & 0.97 & 0.68 & 0.97 & 0.85 & 0.32 & 0.77 \\
\hline INM-CM4-8 & 0.77 & 0.62 & 0.92 & 0.91 & 0.74 & 0.96 & 0.96 & 0.25 & 0.83 \\
\hline INM-CM5-0 & 0.76 & 0.72 & 0.95 & 0.91 & 0.71 & 0.96 & 0.65 & -0.80 & 0.62 \\
\hline IPSL-CM6A-LR & 0.74 & 0.48 & 0.86 & 0.97 & 0.64 & 0.97 & 0.84 & -1.20 & 0.72 \\
\hline MIROC6 & 0.76 & 0.49 & 0.89 & 0.95 & 0.50 & 0.93 & 0.96 & -2.60 & 0.80 \\
\hline MPI-ESM1-2-HR & 0.74 & 0.54 & 0.89 & 0.95 & 0.49 & 0.93 & 0.97 & -5.60 & 0.80 \\
\hline MPI-ESM1-2-LR & 0.86 & 0.78 & 0.92 & 0.93 & 0.53 & 0.86 & 0.93 & -6.80 & 0.60 \\
\hline MRI-ESM2-0 & 0.84 & 0.40 & 0.77 & 0.90 & 0.46 & 0.93 & 0.85 & -10.6 & 0.56 \\
\hline NESM3 & 0.67 & 0.62 & 0.91 & 0.80 & 0.56 & 0.90 & 0.92 & -15.8 & 0.64 \\
\hline
\end{tabular}

\subsection{Bias Correction}

Figure 5 shows the bias in MME mean Pre, Tmx, and Tmn of selected GCMs against the observation GPCC rainfall and CRU temperature before and after the bias correction for the reference period (1975-2014). The raw ensemble GCMs show an overall bias of -40 to $55 \%$ in Pre, where Pre was overestimated in most regions except a small area in the north (Fig. 5a). On the other hand, Tmx and Tmn showed a high negative bias or underestimation in the highlands and a high positive bias in desert regions (Fig. 5c,e). The QDM approach reduced the bias associated with the selected GCMs. The results indicate bias in Pre after applying QDM was in $\pm 20 \%$ ((Fig. 5b,d,f). However, in most regions, the bias was only $\pm 10 \%$. Similarly, biases in Tmx and Tmn were reduced to $\pm 1.6^{\circ} \mathrm{C}$ after applying QDM.

\subsection{Projected change in climate}

A multimodal mean ensemble (MME) was developed from the three highest-ranked models. Figure 6presents the geographical distribution of the projected changes in annual Pre for two future periods under different SSPs estimated using MME mean. The Figure 6 shows changes in Pre in the range of -40 to more than $60 \%$ for different SSPs for the wo periods. Desert areas were projected with the highest decrease, while the highest increase was projected in the highlands, especially for the late period under SSP5-8.5.

Figure 7 shows the changes of Tmx over Afghanistan. The results showed an increase in Tmx for all scenarios and time horizons by 1.3 to $5.3{ }^{\circ} \mathrm{C}$. The lowest increase was projected for SSP1-2.6 in the country's south in the early period, while the highest increase was 
projected for SSP5-8.5 in the late period in the northeast. The spatial pattern in the change in Tmn over Afghanistan revealed a similar increase to $\mathrm{Tmx}$ (Fig. 8). The projected increase was in the range of 1.3 to $5.4^{\circ} \mathrm{C}$.

\subsection{Climate projections over different climatic regions}

The projection of seasonal Pre, Tmx, and Tmn for different scenarios in each climatic region during the far future are shown in (Fig. 9). The results showed increased temperature and decreased precipitation in all climate zones for different scenarios, except zone 1 (Hindu Kush region). An increase in Pre is projected in zone 1 during the rainy seasons.

The future projection of Tmx and Tmn in different climate zones for three SSPs are shown in (Fig. 10) and (Fig. 11), respectively. The line in each figure shows the mean projection, and the band represents the projections with a $95 \%$ confidence interval. The figures show a gradual increase in both Tmx and Tmn for all scenarios in all regions. The highest increase in Tmx and Tmn was projected in the highland region between 5.3 and $5.4{ }^{\circ} \mathrm{C}$ for SSP5-85 at the end of the century. This may lead to an increase in snow melting stored in high elevated mountains. Besides, a high increase in Tmx and Tmn was also projected in zone 5 (southern plateau).

\section{Discussions}

Performance of CMIP6-GCMs was assessed in simulating GPCC Pre and CRU Tmx and Tmn over Afghanistan for the period 19752014. The comparison was made by re-gridding the GCMs to $1^{\circ} \times 1^{\circ}$. GCMs' skill has been compared for different spatial resolutions in the previous studies, ranging from 0.25 to $2^{\circ}$ (Khan et al., 2018; V. Mishra et al., 2020; Ahmed, Sachindra, et al., 2019; Sa'adi et al., 2020; S. K. Mishra et al., 2018). However, most studies used $1^{\circ} \times 1^{\circ}$ resolution for a fair comparison, as it is near to mean resolution (Salehie \& Tam, 2021; Yazdandoost et al., 2021; Rivera \& Arnould, 2020). It is expected that comparison using mean resolution provided the best estimation of models' performance.

The GCMs skill is estimated considering the capability in simulating the mean, dispersion, and distribution of observed climatology. They should also be capable of replicating a similar climatological pattern (Xin et al., 2020). Therefore, multiple metrics are required to fairly assess GCM's skills. In this study, KGE, CC, and SS were employed to determine GCM's skill in reconstructing observed rainfall and temperature patterns with less bias and similar distribution over 1975-2014. The use of a robust algorithm (CP) to integrate performance metrics has helped to provide an unbiased assessment of GCM's performance.

GCMs should provide skill in simulating both rainfall and temperature (Tmx and Tmn) together, as these three variables are needed for climate change studies (Hamed, 2021). For example, assessing climate change implications on floods requires precipitation and temperature to estimate snowmelt. This study considers these three climate variables together for GCM ranking. Therefore, the selected GCMs can be recommended for Afghanistan's climate change effect evaluation and adaptation planning.

The present study showed a possible precipitation reduction in most of Afghanistan. A dry climate dominates the country, and therefore, water is a major hindrance to crop agriculture and food security. The decrease in rainfall would make the situation worse. The precipitation in the country is projected to reduce more in low rainfall regions and increase in the areas that receive the highest rainfall. This indicates the dry region would become drier and the wet region wetter in the future. This would increase aridity and crop failure risk in the dry region, which covers most of the country.

The results showed a higher rise in temperature in the Hindu Kush region for all SSPs and time horizons. The precipitation in the wet (summer) season is also projected to increase in the region. Increased temperature may lead to an increase in snow melting stored in high elevated mountains. This may cause a large increase in river discharge in the summer. Increased rainfall would aggravate the condition and cause a sharp rise in floods in the region. The northeastern Hindu Kush are is most susceptible to hydrological disasters like floods in Afghanistan (OCHA, 2016) Climate change may increase flood frequency and severity in the region in the future.

\section{Conclusions}

This study assessed the skill of 19 CMIP6 GCMs in simulating present precipitation and temperature over different climatic regions of Afghanistan. Compromise programming based on three robust statistical metrics and a rating metric was employed to judge GCMs' performance. The study identified three GCMs as most suitable for climate projections over Afghanistan. The MMEs of selected GCMs revealed a large rise in maximum and minimum temperature for all regions for SSPs. In contrast, both increase and decrease in precipitation over the country were projected. A higher increase in precipitation was projected in the highlands and a decrease in the 
deserts. The methods adopted in this study can be used in other regions to select suitable set GCM and future climate simulation. Future work may assess the relative skills of CMIP6 with CMIP5 to recommend rationalization of existing policy based on CMIP5. Besides, the GCMs selected in this study can be employed to evaluate the climate change implications in hydrometeorological hazards in the future. Specifically, GCMs' daily simulations can be used for assessing the possible changes in climatic extremes.

\section{Declarations}

Acknowledgement: The authors are thankful to the Climatic Research Unit of University of East Anglia, Global Precipitation Climatology Center (GPCC) and WCRP Coupled Model Intercomparison Project (Phase 6) website of Program for Climate Model Diagnosis \& Intercomparison (PCMDI) for providing gridded precipitation and temperature data available through their data portal.

Funding: The authors declare that no funds, grants, or other support were received during the preparation of this manuscript

Availability of data: All the data are available in the public domain at the links provided in the texts

Availability of code: The codes used for the processing of data can be provided on request to the corresponding author.

Authors contribution: All the authors contributed to conceptualizing and designing the study. Mohammad Naser Sediqi gathered data; the programming code was written by Mohammad Naser Sediqi and Vempi Satriya Adi Hendrawan; the initial draft of the paper was prepared by Mohammad Naser Sediqi and Vempi Satriya Adi Hendrawan; the article was repeatedly revised to generate the final version by Daisuke Komori.

Consent to participate The authors declare that they have consent to participate in this paper.

Ethics approval The authors declare that they have consent to publish in this journal.

Competing interest The authors declare no competing interests.

\section{References}

1. Ahmed K, Sachindra DA, Shahid S, Demirel MC, Chung ES (2019) Selection of multi-model ensemble of general circulation models for the simulation of precipitation and maximum and minimum temperature based on spatial assessment metrics. Hydrol Earth Syst Sci 23(11):4803-4824. https://doi.org/10.5194/hess-23-4803-2019

2. Ahmed K, Shahid S, Wang X, Nawaz N, Najeebullah K (2019) Evaluation of gridded precipitation datasets over arid regions of Pakistan. Water (Switzerland) 11(2). https://doi.org/10.3390/w11020210

3. Aich V, Akhundzadah NA, Knuerr A, Khoshbeen AJ, Hattermann F, Paeth H, Scanlon A, Paton EN (2017) Climate change in Afghanistan deduced from reanalysis and coordinated regional climate downscaling experiment (CORDEX)-South Asia simulations. Climate 5(2). https://doi.org/10.3390/cli5020038

4. Dessai S, Hulme M (2007) Assessing the robustness of adaptation decisions to climate change uncertainties: A case study on water resources management in the East of England. Glob Environ Change 17(1):59-72. https://doi.org/10.1016/j.gloenvcha.2006.11.005

5. Ghulami M (2018) Assessment of climate change impacts on water resources and agriculture in data-scarce Kabul basin, To cite this version : Thèse de doctorat Masoud Ghulami Evaluation des impacts du changement climatique sur la ressource en eau et I' agriculture dans le

6. HAJIHOSEINI H, HAJIHOSSEINI M, MORID NAJAFIA, DELAVAR M (2015) Assessment of Changes in Hydro-Meteorological Variables Upstream of Helmand Basin During the Last Century Using Cru Data and Swat Model. Iran-Water Resources Research 10(3):38-52. https://www.sid.ir/en/journal/ViewPaper.aspx?id=455590

7. Hamed MM (2021) Intercomparison of Historical Simulation and Future Projection of Rainfall and Temperature by CMIP5 and CMIP6 GCMs Over Egypt (pp. 1-32)

8. Harris I, Jones PD, Osborn TJ, Lister DH (2014) Updated high-resolution grids of monthly climatic observations - the CRU TS3.10 Dataset. Int J Climatol 34(3):623-642. https://doi.org/10.1002/joc.3711

9. Hassanyar H, Tsutsumi JG, Nakamatsu R (2016) The longterm trend of temperature and precipitation of Kunduz River Basin, Afghanistan 4(6):103-109. www.ijtra.com 
10. HASSANYAR MH, Giorgos TSUTSUMI, OMID SM (2020) the Analysis of Temporal Variability, Trend of Precipitation and River Discharge of Kunduz River Basin, Afghanistan. International Journal of Engineering Technologies and Management Research 5(4):69-78. https://doi.org/10.29121/ijetmr.v5.i4.2018.210

11. Hassanyar MH, Tsutsumi J (2017) Multi-model Ensemble Climate Change Projection for Kunduz River Basin, Afghanistan under Representative Concentration Pathways. Modern Environmental Science and Engineering 03(05):291-301.

https://doi.org/10.15341/mese(2333-2581)/05.03.2017/001

12. Iqbal Z, Shahid S, Ahmed K, Ismail T, Ziarh GF, Chung ES, Wang X (2021) Evaluation of CMIP6 GCM rainfall in mainland Southeast Asia. Atmos Res 254(January):105525. https://doi.org/10.1016/j.atmosres.2021.105525

13. Kamruzzaman M, Shahid S, Islam AT, Hwang S, Cho J, Zaman MAU, Ahmed M, Rahman MM, Hossain MB (2021) Comparison of CMIP6 and CMIP5 model performance in simulating historical precipitation and temperature in Bangladesh: a preliminary study. Theoret Appl Climatol 145(3-4):1385-1406. https://doi.org/10.1007/s00704-021-03691-0

14. Khan N, Shahid S, Ahmed K, Ismail T, Nawaz N, Son M (2018) Performance assessment of general circulation model in simulating daily precipitation and temperature using multiple gridded datasets. Water (Switzerland) 10(12).

https://doi.org/10.3390/w10121793

15. Lyimo JG, Kangalawe RY (2011) Vulnerability and adaptive strategies to the impact of climate change and variability. The case of rural households in semi-arid Tanzania. Environmental Economics 1(2):89-97. https://www.businessperspectives.org/images/pdf/applications/publishing/templates/article/assets/3695/ee_2010_2_Lyimo.pdf

16. Manawi SMA, Nasir KAM, Shiru MS, Hotaki SF, Sediqi MN (2020) Urban Flooding in the Northern Part of Kabul City: Causes and Mitigation. Earth Systems and Environment 4(3):599-610. https://doi.org/10.1007/s41748-020-00165-7

17. Mishra SK, Sahany S, Salunke P, Kang IS, Jain S (2018) Fidelity of CMIP5 multi-model mean in assessing Indian monsoon simulations. Npj Climate and Atmospheric Science 1(1). https://doi.org/10.1038/s41612-018-0049-1

18. Mishra V, Bhatia U, Tiwari AD (2020) Bias-corrected climate projections for South Asia from Coupled Model Intercomparison Project-6. Scientific Data 7(1):1-13. https://doi.org/10.1038/s41597-020-00681-1

19. Mohanty A, Mishra M, Sharma D, Ibrahimzada MW (2012) Assessing the hydrological impacts of climate change on the AMU Darya River, Afghanistan. In Community, Environment and Disaster Risk Management (Vol. 11, Issue 2012). Emerald Group Publishing Ltd. https://doi.org/10.1108/S2040-7262(2012)0000011009

20. Muhammad A, Kumar Jha S, Rasmussen PF (2017) Drought Characterization for a Snow-Dominated Region of Afghanistan. J Hydrol Eng 22(8):05017014. https://doi.org/10.1061/(asce)he.1943-5584.0001543

21. Nengroo IA, Of F, Science S (2012) Irrigation potential and levels of agricultural development in afghanistan thesis

22. OCHA (2016) UNITED NATIONS OFFICE FOR THE COORDINATION OF HUMANITARIAN AFFAIRS

23. Olson DM, Dinerstein E, Wikramanayake ED, Burgess ND, Powell GVN, Underwood EC, D'Amico JA, Itoua I, Strand HE, Morrison JC, Loucks CJ, Allnutt TF, Ricketts TH, Kura Y, Lamoreux JF, Wettengel WW, Hedao P, Kassem KR (2001) Terrestrial ecoregions of the world: A new map of life on Earth. Bioscience 51(11):933-938. https://doi.org/10.1641/0006-

3568(2001)051[0933:TEOTWA]2.0.C0;2

24. Omerkhil N, Chand T, Valente D, Alatalo JM, Pandey R (2020) Climate change vulnerability and adaptation strategies for smallholder farmers in Yangi Qala District, Takhar, Afghanistan. Ecological Indicators, 110(June 2019). https://doi.org/10.1016/j.ecolind.2019.105863

25. Qutbudin I, Shiru MS, Sharafati A, Ahmed K, Al-Ansari N, Yaseen ZM, Shahid S, Wang X (2019) Seasonal drought pattern changes due to climate variability: Case study in Afghanistan. Water (Switzerland) 11(5). https://doi.org/10.3390/w11051096

26. Rahman MH, ur, Ahmad A, Wang X, Wajid A, Nasim W, Hussain M, Ahmad B, Ahmad I, Ali Z, Ishaque W, Awais M, Shelia V, Ahmad S, Fahd S, Alam M, Ullah H, Hoogenboom G (2018) Multi-model projections of future climate and climate change impacts uncertainty assessment for cotton production in Pakistan. Agric For Meteorol 253-254(February):94-113. https://doi.org/10.1016/j.agrformet.2018.02.008

27. Rao N, Lawson ET, Raditloaneng WN, Solomon D, Angula MN (2019) Gendered vulnerabilities to climate change: insights from the semi-arid regions of Africa and Asia. Climate Dev 11(1):14-26. https://doi.org/10.1080/17565529.2017.1372266

28. Rivera JA, Arnould G (2020) Evaluation of the ability of CMIP6 models to simulate precipitation over Southwestern South America: Climatic features and long-term trends (1901-2014). Atmospheric Research, 241(December 2019), 104953.

https://doi.org/10.1016/j.atmosres.2020.104953

Page $10 / 22$ 
29. Sa'adi Z, Shiru MS, Shahid S, Ismail T (2020) Selection of general circulation models for the projections of spatio-temporal changes in temperature of Borneo Island based on CMIP5. Theoret Appl Climatol 139(1-2):351-371.

https://doi.org/10.1007/s00704-019-02948-z

30. Salehie O, Tam TH (2021) Selection of CMIP6 GCM With Projection of Climate Over The Amu Darya River Basin. 1-27

31. Salman SA, Shahid S, Ismail T, Ahmed K, Wang XJ (2018) Selection of climate models for projection of spatiotemporal changes in temperature of Iraq with uncertainties. Atmos Res 213(April):509-522. https://doi.org/10.1016/j.atmosres.2018.07.008

32. Savage M, Dougherty B, Hamza M, Butterfield R, Bharwani S (2009) Socio-Economic Impacts of Climate Change in Afghanistan (DFID) - Executive Summary. http://livelihoodsrc.dfid.gov.uk/uploads/File/2007447_AfghanCC_ExS_09MAR09.pdf

33. Sediqi MN, Shiru MS, Nashwan MS, Ali R, Abubaker S, Wang X, Ahmed K, Shahid S, Asaduzzaman M, Manawi SMA (2019) Spatiotemporal pattern in the changes in availability and sustainability ofwater resources in Afghanistan. Sustainability (Switzerland) 11(20). https://doi.org/10.3390/su11205836

34. Shiru MS, Shahid S, Dewan A, Chung ES, Alias N, Ahmed K, Hassan QK (2020) Projection of meteorological droughts in Nigeria during growing seasons under climate change scenarios. Sci Rep 10(1):1-18. https://doi.org/10.1038/s41598-020-67146-8

35. Shiru MS, Shahid S, Shiru S, Chung ES, Alias N, Ahmed K, Dioha EC, Sa'adi Z, Salman S, Noor M, Nashwan MS, Idlan MK, Khan N, Momade MH, Houmsi MR, Iqbal Z, Ishanch Q, Sediqi MN (2020) Challenges in water resources of lagos mega city of nigeria in the context of climate change. Journal of Water and Climate Change 11(4):1067-1083. https://doi.org/10.2166/wcc.2019.047

36. Sidiqi M, Shrestha S, Ninsawat S (2018) Projection of climate change scenarios in the Kabul River Basin, Afghanistan. 114(6)

37. Song YH, Shahid S, Chung ES (2021) Differences in multi-model ensembles of CMIP5 and CMIP6 projections for future droughts in South Korea. Int J Climatol 1-29. https://doi.org/10.1002/joc.7386

38. Tschudin V (2008) Country profile: Afghanistan. In Nursing Ethics (Vol. 11, Issue 5, pp. 517-525). https://doi.org/10.1191/0969733004ne730xx

39. Xin X, Wu T, Zhang J, Yao J, Fang Y (2020) Comparison of CMIP6 and CMIP5 simulations of precipitation in China and the East Asian summer monsoon. Int J Climatol 40(15):6423-6440. https://doi.org/10.1002/joc.6590

40. Yazdandoost F, Moradian S, Izadi A, Aghakouchak A (2021) Evaluation of CMIP6 precipitation simulations across different climatic zones: Uncertainty and model intercomparison. Atmos Res 250(1346):105369.

https://doi.org/10.1016/j.atmosres.2020.105369

41. Zamani Y, Hashemi Monfared SA, Azhdari moghaddam M, Hamidianpour M (2020) A comparison of CMIP6 and CMIP5 projections for precipitation to observational data: the case of Northeastern Iran. Theoret Appl Climatol 142(3-4):1613-1623. https://doi.org/10.1007/s00704-020-03406-x

42. Zeleny M, Cochrane JL (1973) Compromise Programming: Multicriteria Decision Making.

\section{Figures}




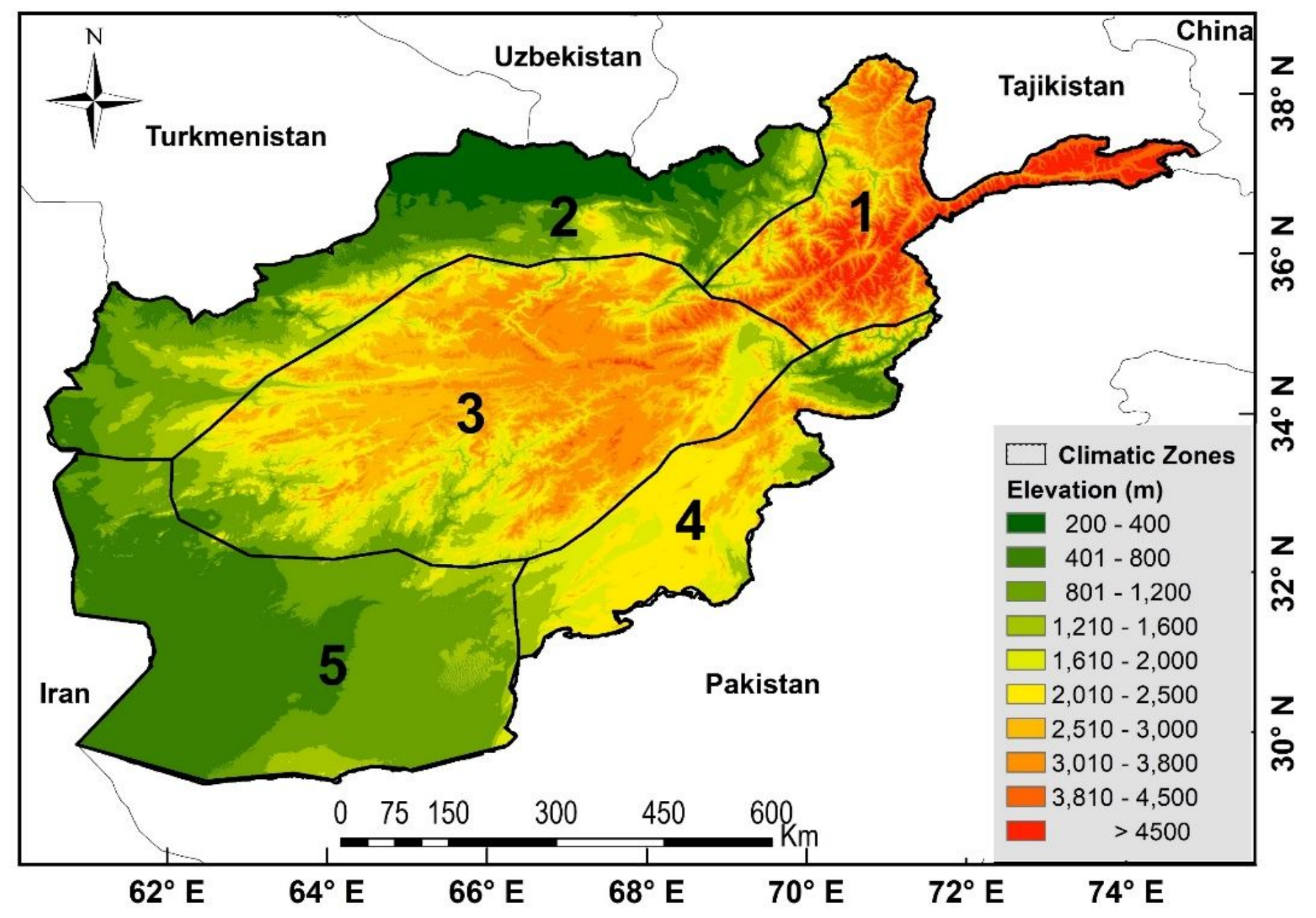

Figure 1

Location with its different topography and different climatic zones of Afghanistan. 

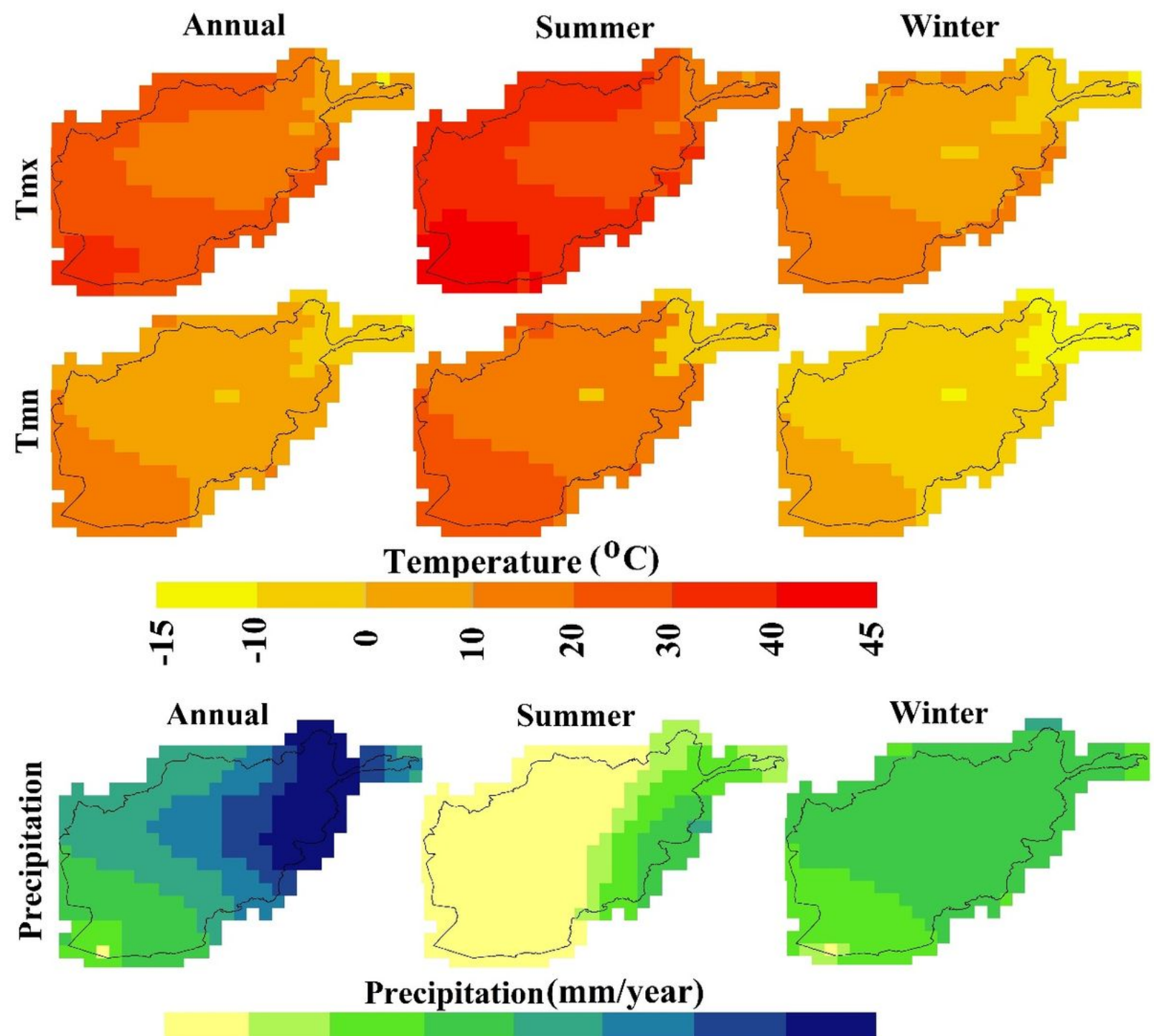

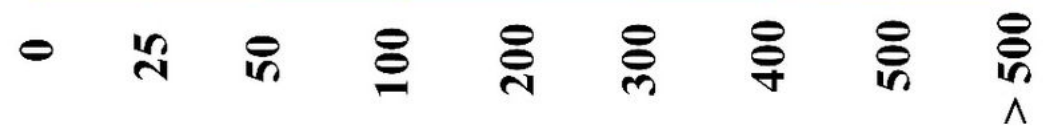

Figure 2

The annual, summer and winter maximum temperature, minimum temperature and precipitation over Afghanistan for 1975-2014. 

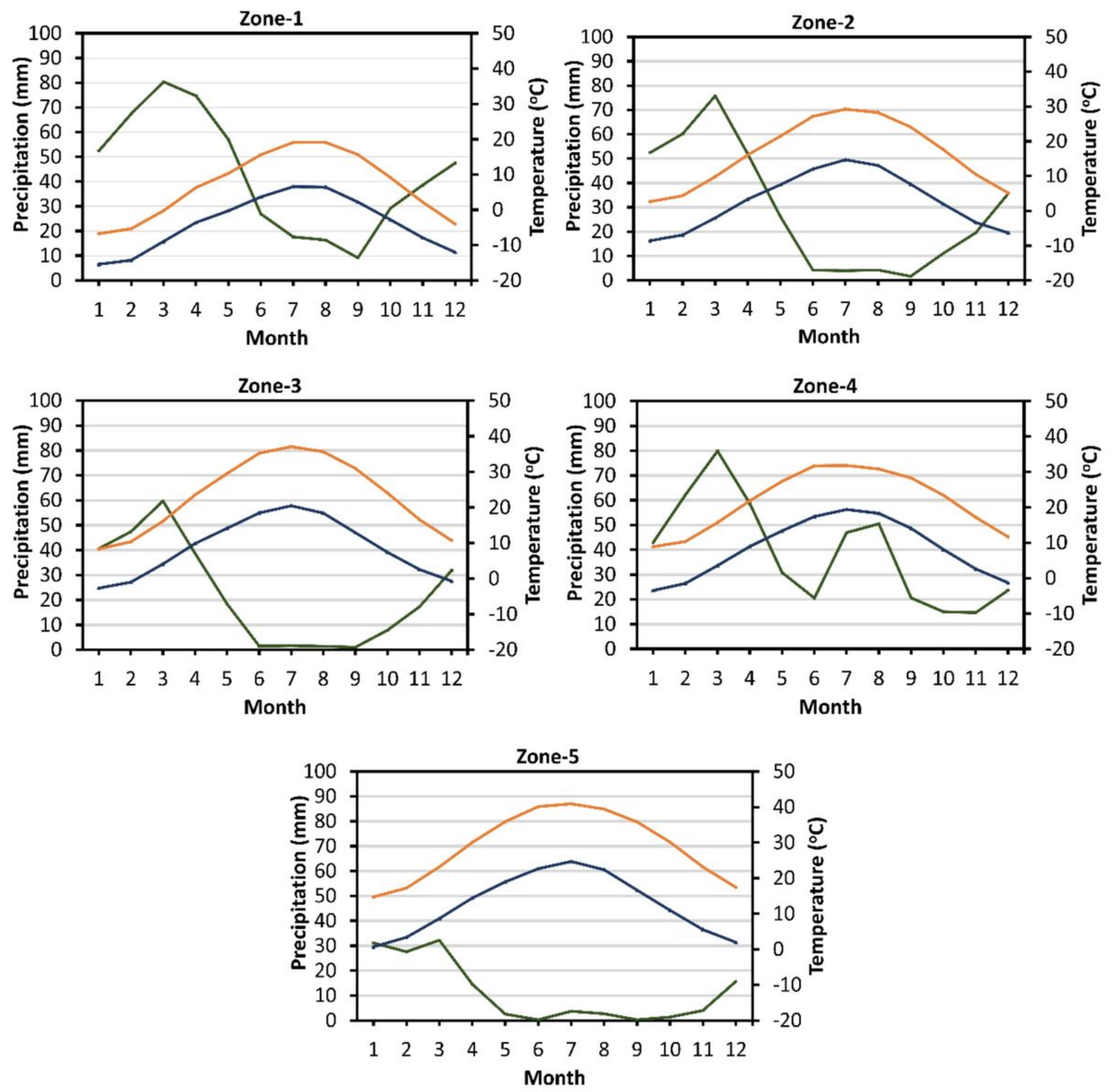

Figure 3

Areal average seasonal precipitation (green), maximum (orange), and minimum temperature in different climatic zones for 1975-2014. 


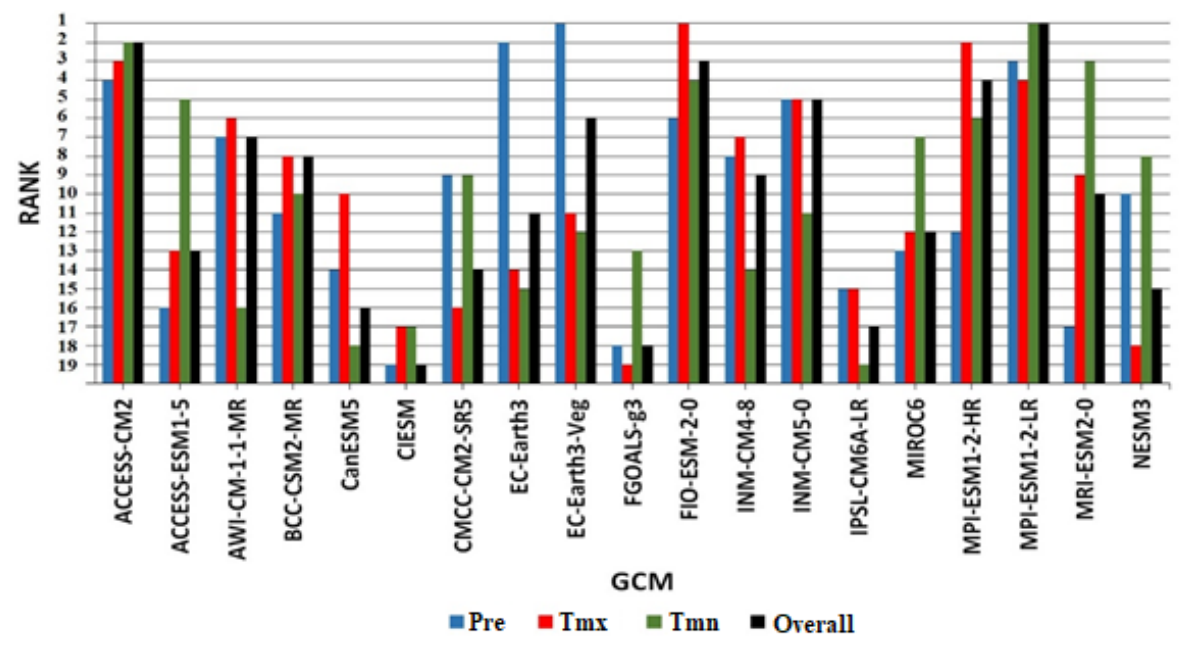

Figure 4

GCM ranking based on the skill in replicating observed precipitation (blue), maximum (red), and minimum temperature (green). The overall rank (black) estimated using the ranking metric algorithm is also shown. 

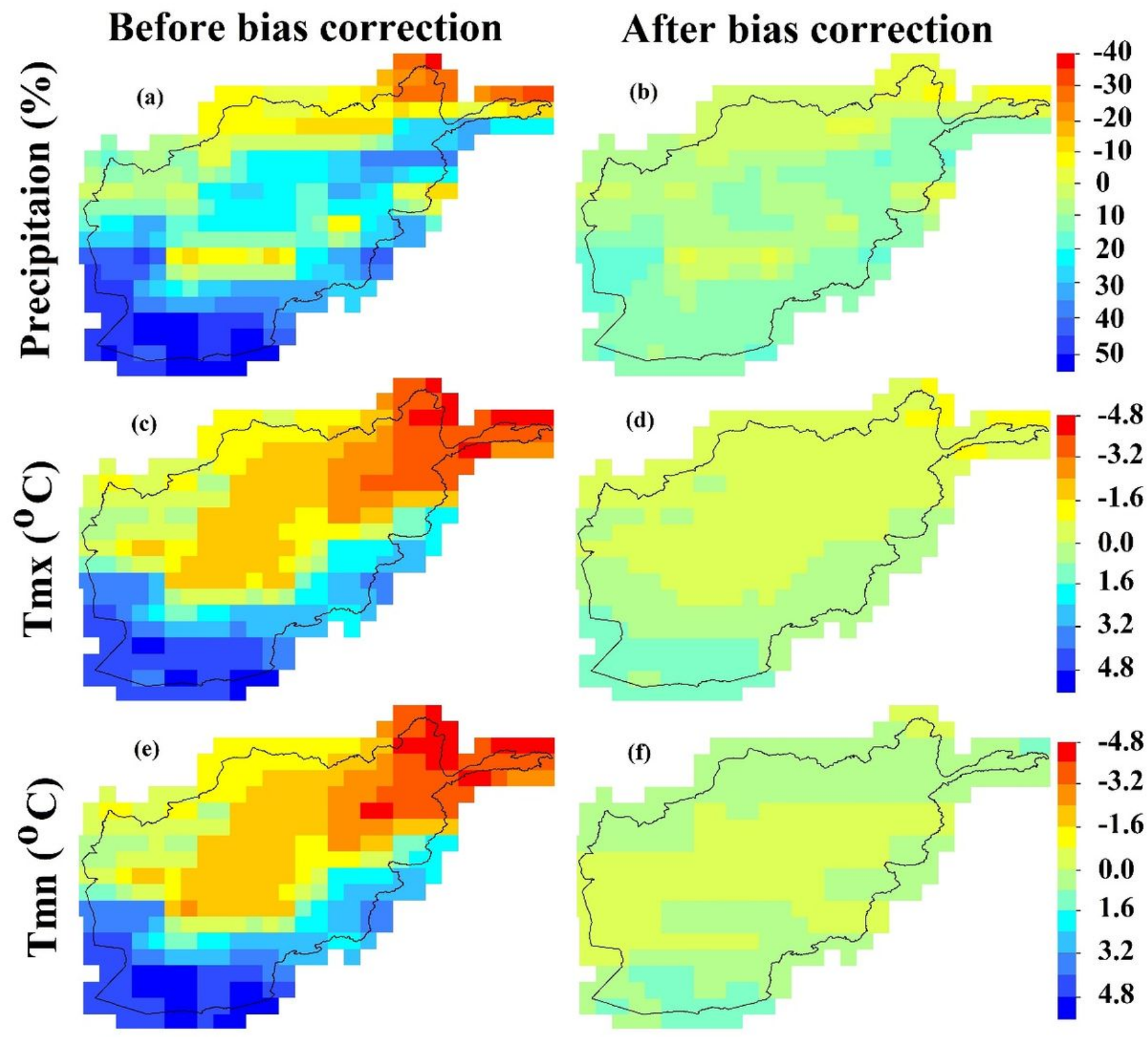

Figure 5

Bias in the ensemble mean of selected CMIP6-GCMs during the reference period (1975-2014). Bias in precipitation (\%) (a,b), maximum temperature $\left({ }^{\circ} \mathrm{C}\right)(\mathrm{c}, \mathrm{d})$ minimum temperature $\left({ }^{\circ} \mathrm{C}\right)(\mathrm{e}, \mathrm{f})$ before and after bias correction. 


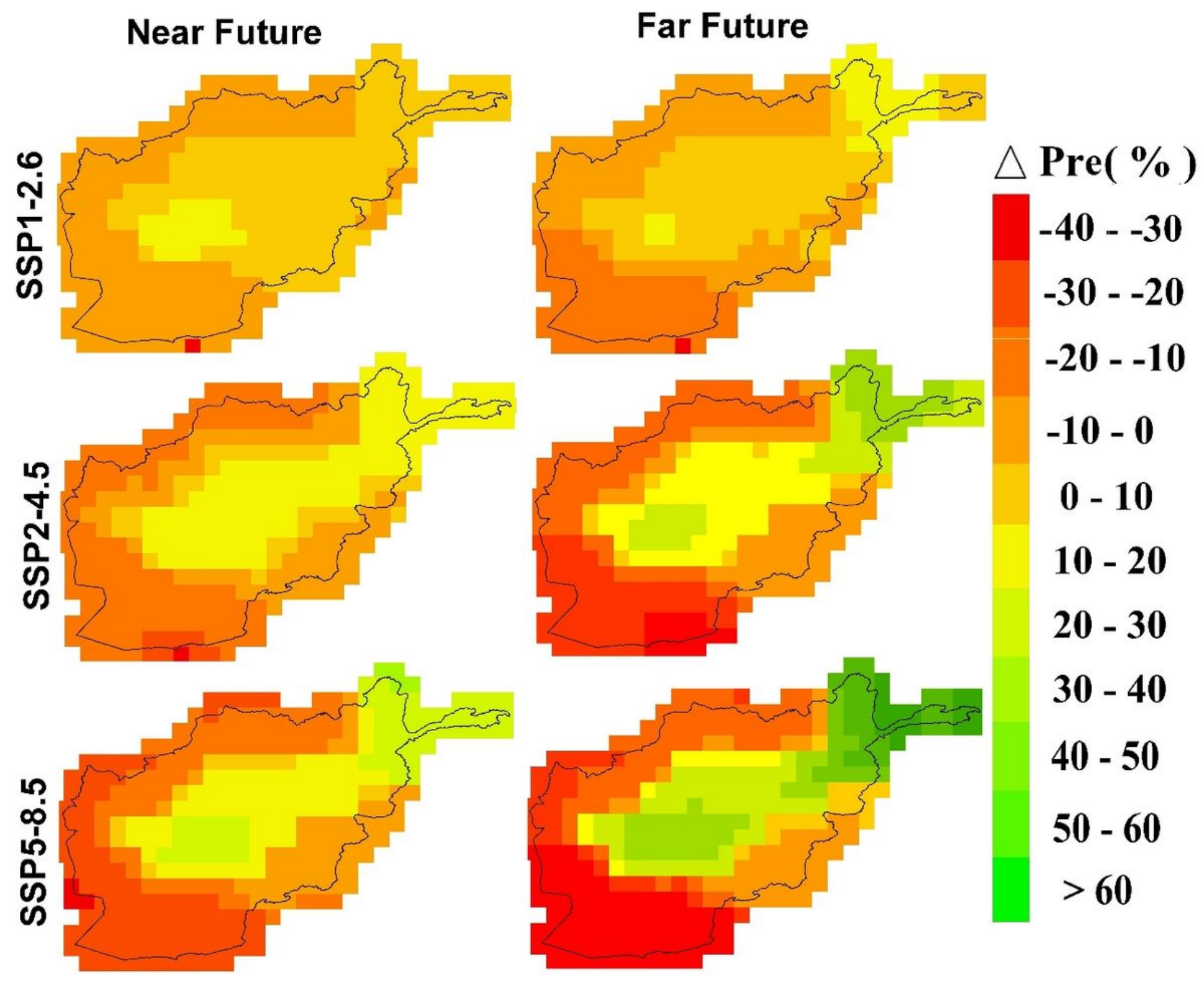

Figure 6

Spatial patterns in precipitation changes over Afghanistan for the early (2020-2059) and late (2060-2099) periods for SSP1-2.6, 2-4.5, and 5-8.5. 

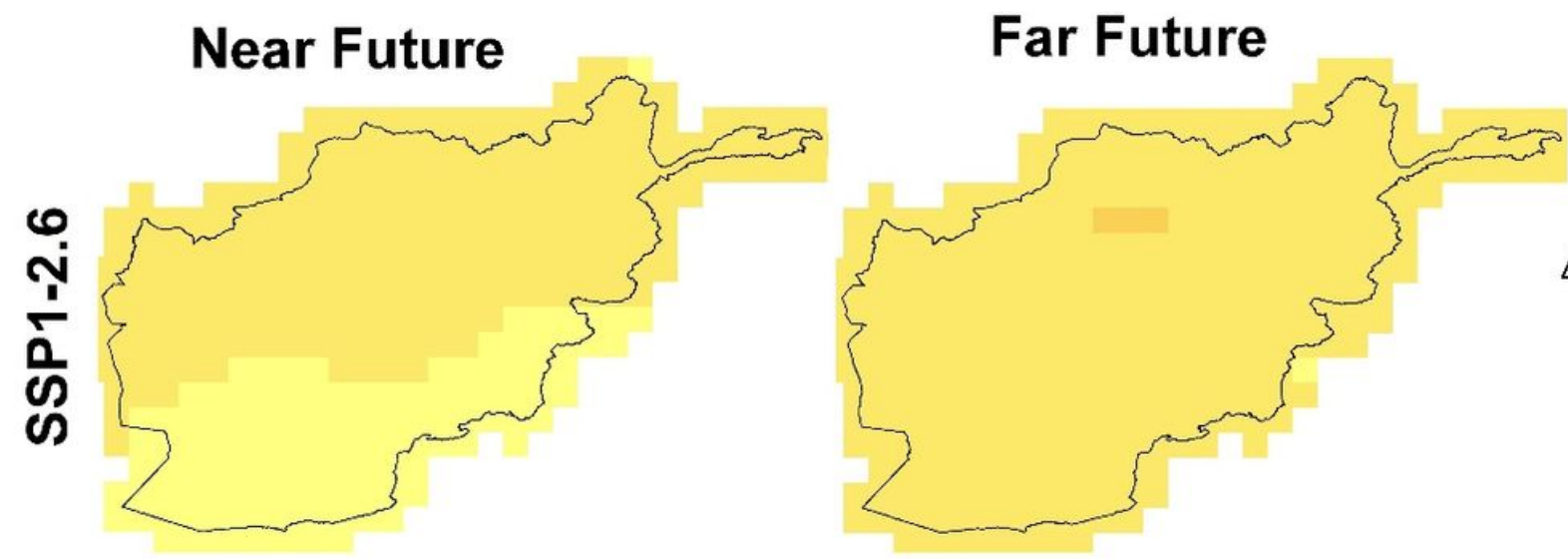

$\triangle \operatorname{Tmx}\left({ }^{\circ} \mathrm{C}\right)$

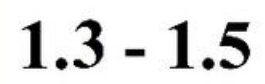

1.5 - 2.0
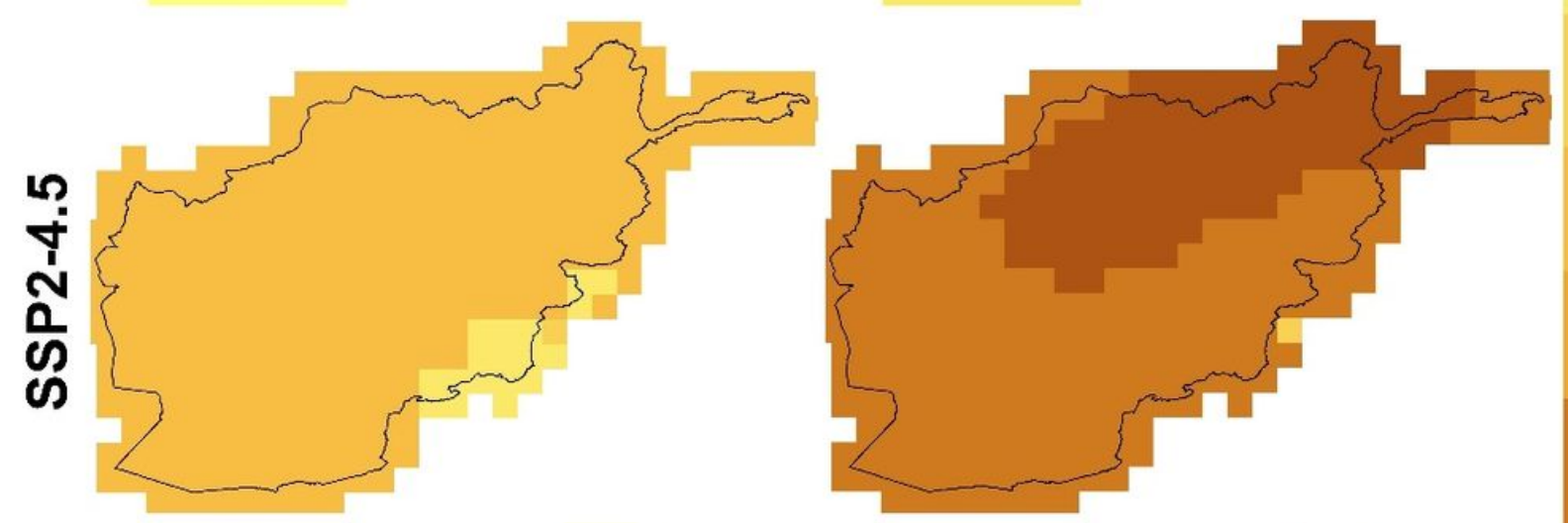

2.0 - 2.5

2.5 - 3.0

3.0 - 3.5

3.5 - 4.0
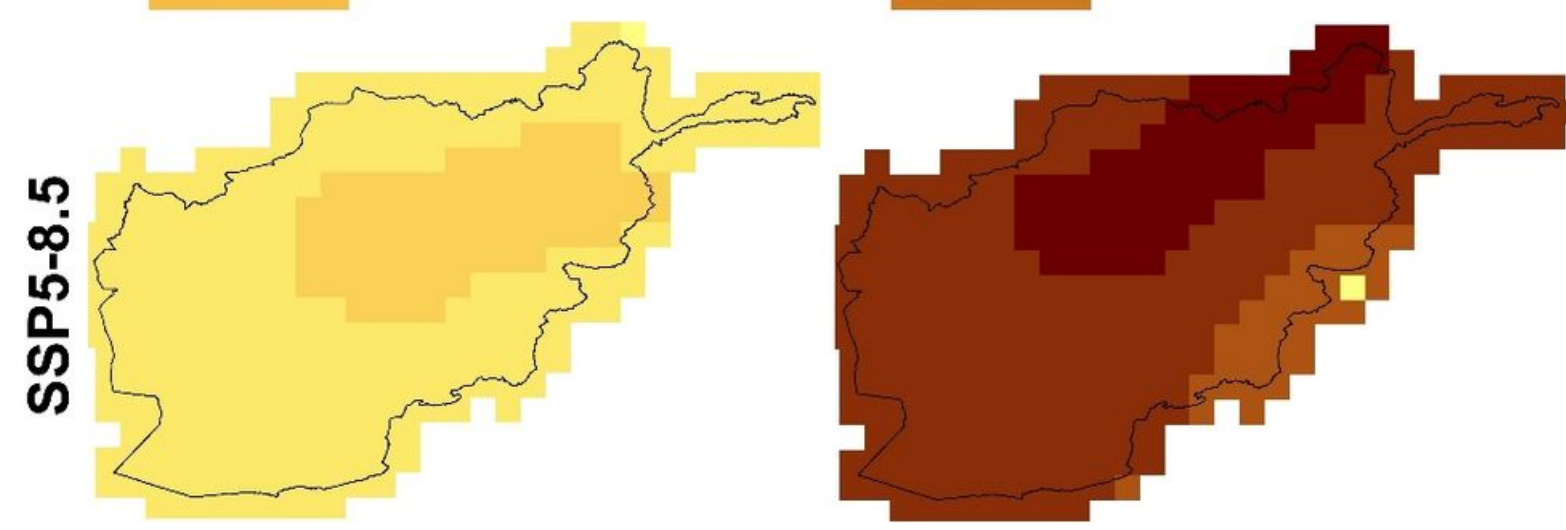

4.0 - 4.5

4.5 - 5.0

$5.0-5.3$

Figure 7

Same as Fig. 6, but for maximum temperature. 

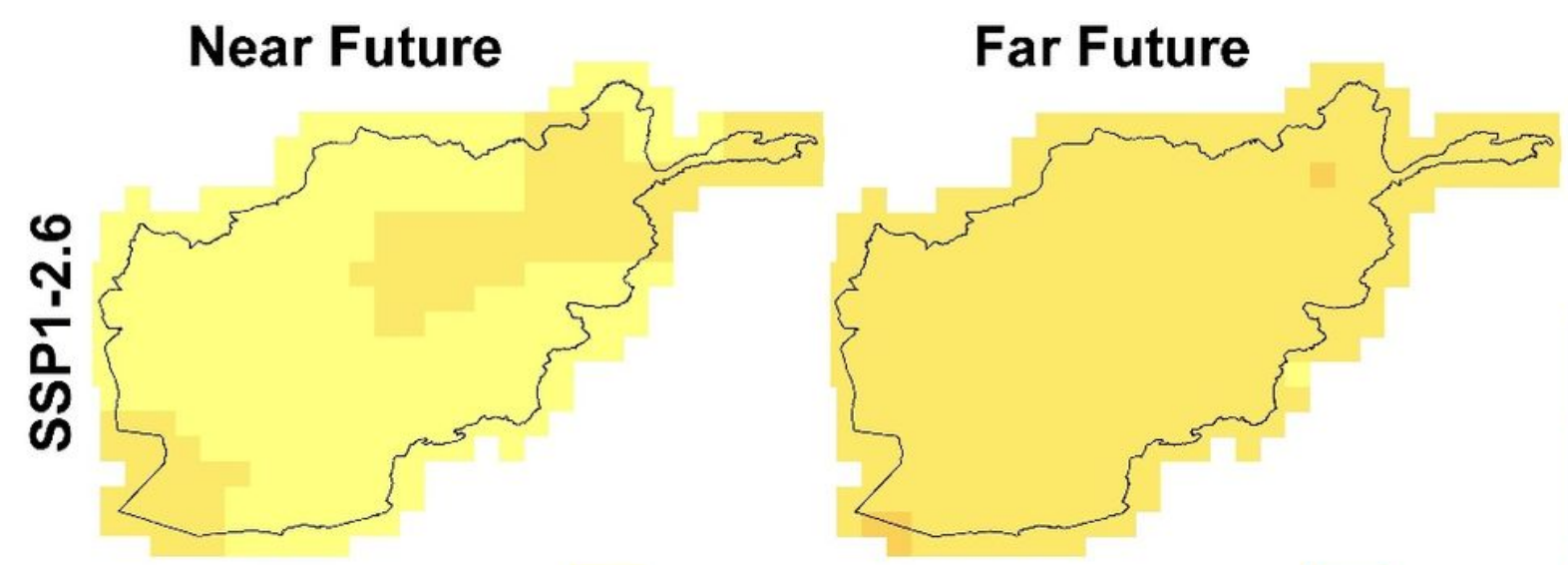

$\triangle \operatorname{Tmn}\left({ }^{\mathbf{0}} \mathrm{C}\right)$
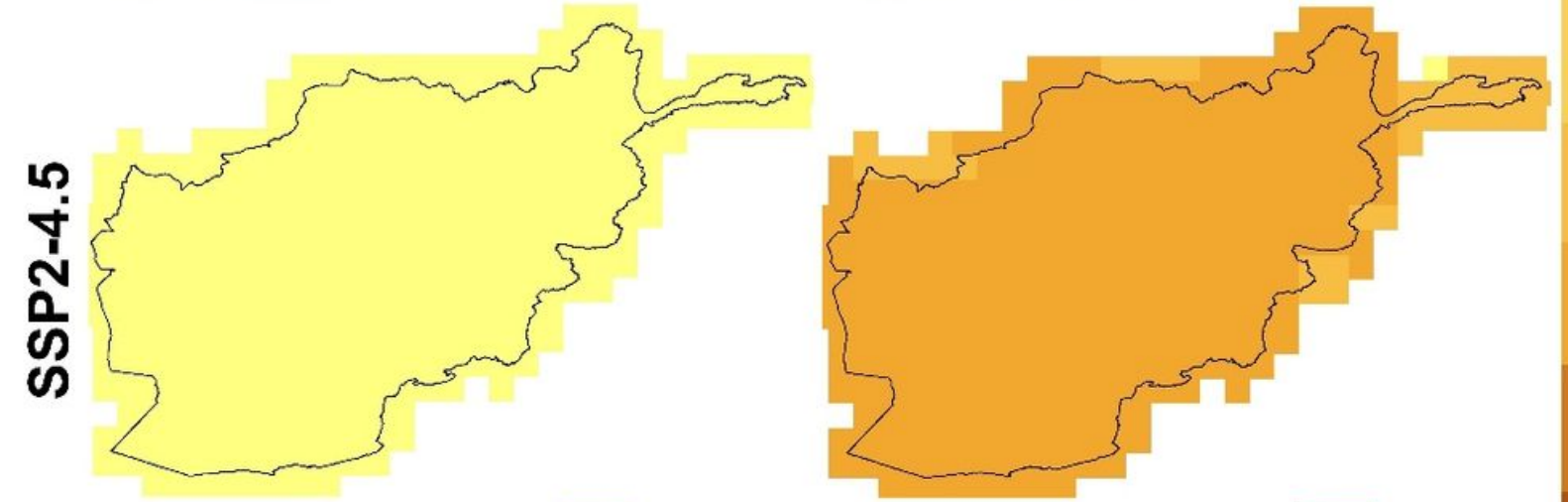

1.3 - 1.5

1.5 - 2.0

2.0 - 2.5

2.5 - 3.0

3.0 - 3.5

3.5 - 4.0
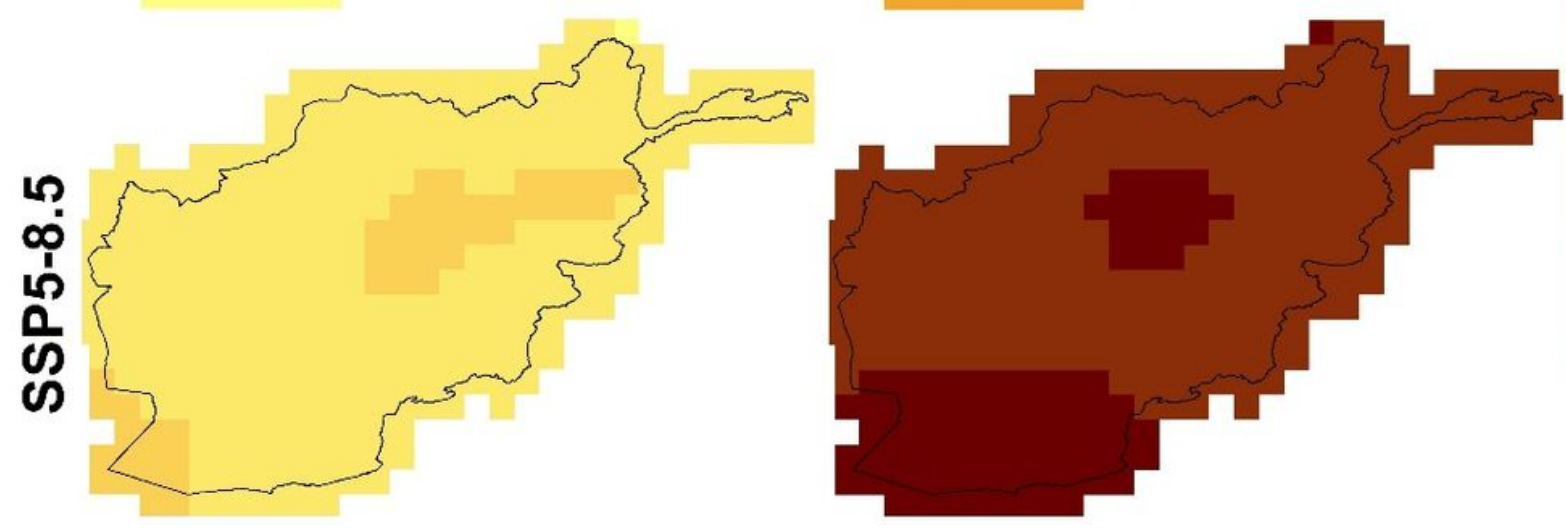

4.0 - 4.5

4.5 - 5.0

5.0 - 5.4

Figure 8

Same as Fig. 6, but for minimum temperature. 
Zone-1

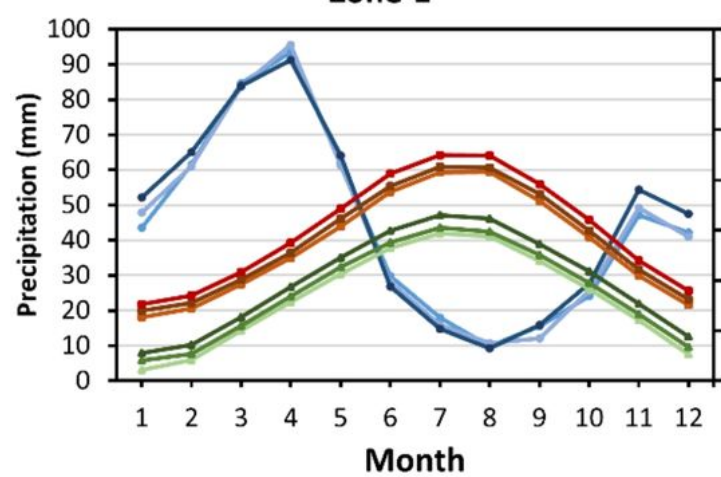

Zone-3

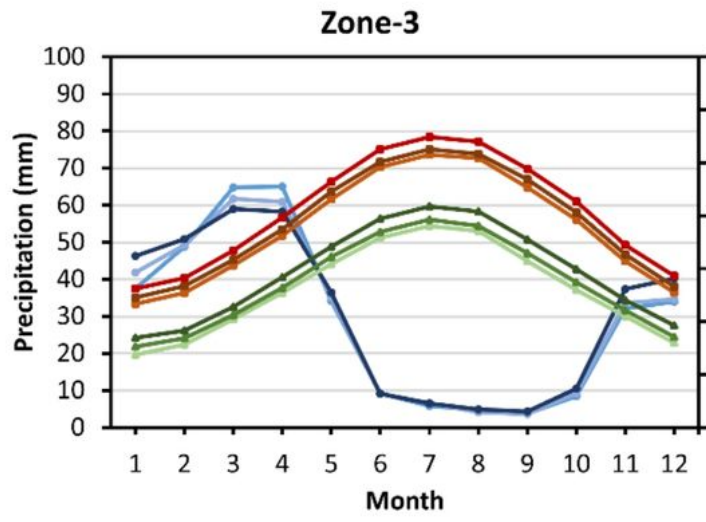

Zone-2
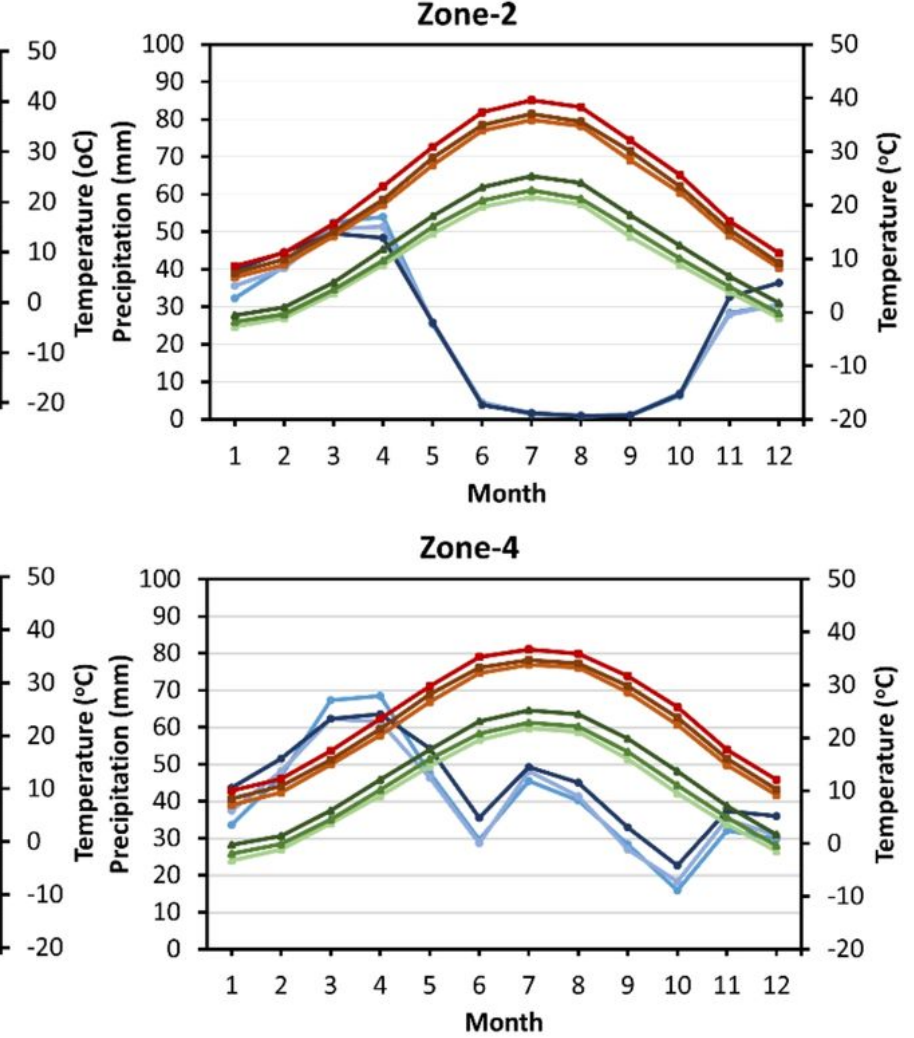

Zone-5

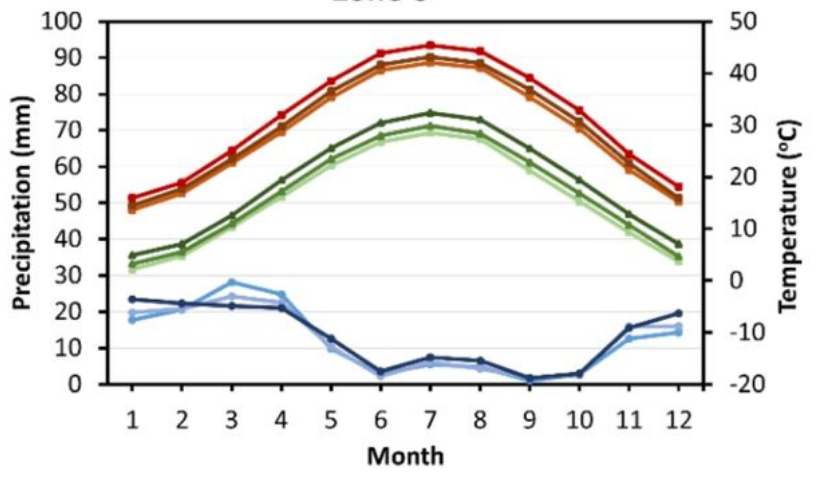

Figure 9

Seasonal projection of precipitation (blue), maximum temperature (red), and minimum temperature (green) in different climatic zones during late period (2060-2099) for three SSPs 


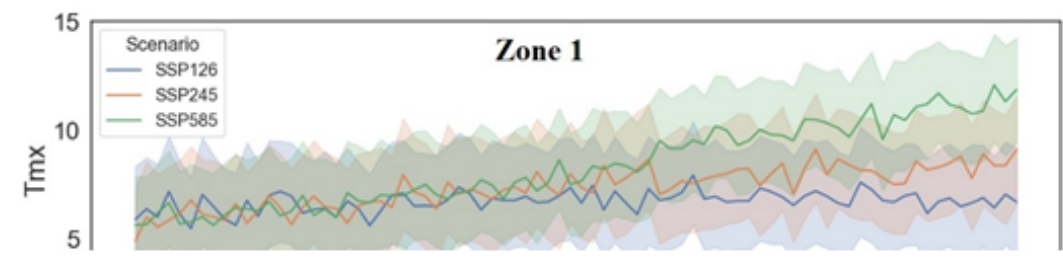

\section{Figure 10}

Projection of maximum temperature $\left({ }^{\circ} \mathrm{C}\right)$ for different scenarios in different climatic zones 


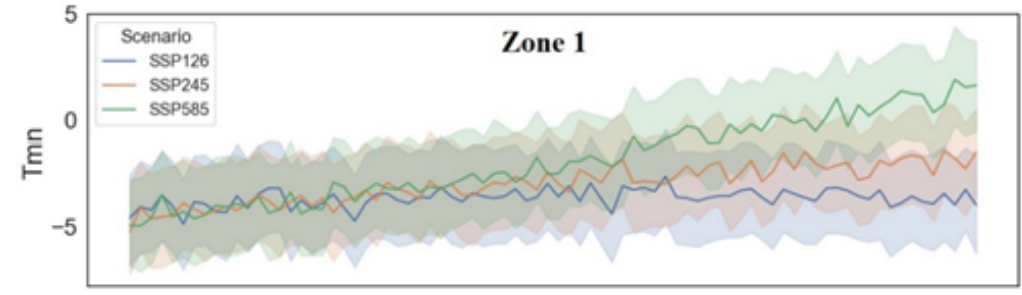

\section{Figure 11}

Projection of minimum temperature $\left({ }^{\circ} \mathrm{C}\right)$ for different scenarios in different climatic zones 